\title{
Associate Degree Program in Telemedia Communications Technology
}

\author{
David B. Beyer P.E. \\ Middlesex County College, Edison, N.J.
}

\section{Introduction}

Under a grant from the National Science Foundation, Middlesex County College faculty is developing a two-year associate in applied science degree program in Telemedia Communications Technology (NSF grant 9602375). As the name implies, telemedia is the transmission of multimedia information over distances. This program will prepare technicians for careers in the telecommunications industry, and indeed, in any organization where technician level telecommunications skills are required. The program is being designed in cooperation with a local high school, so that provision can be made for smooth transition from high school to this program. It is anticipated that articulation with four-year colleges will allow students to continue towards a bachelor degree. The first class will enter this program in the fall of 1998.

It is expected that graduates will find ready employment in industry. Our industrial partners have informed us that many employment opportunities exist in such areas as network installation and maintenance, installation of video-conferencing equipment, cable installation, testing and troubleshooting. The major components of the program are intended to maximize student competencies in these areas. A solid core of mathematics and science, development of oral and written communications skills, social science, and humanities are incorporated into the program.

\section{Procedure}

This curriculum will be implemented in a project-centered approach, in a facility best described as a studio environment. There is to be no differentiation between lecture, recitation, and laboratory. Projects and activities will be the vehicle of instruction as opposed to the standard lecture and separate laboratory. All activities associated with a course will be conducted in the same room. The room will have computer terminals and equipment available for any construction or assembly required for projects. The core technical support topics of mathematics, science, and communications will be delivered on a "just in time" basis. As material is covered by the major technical courses, the supporting material will be introduced and developed within the mathematics or science course, timed to be introduced to students as needed.

The general approach in the ongoing development of this program was to create a list of technician competencies upon which the actual courses would be developed. The essentials of this list were provided by our industrial partners. These include: AT\&T Corp., Siemens Rolm, York Engineering, Visual Media Group, Madge Networks, Inc., Lucent, and Eastern Datacom.

The entrance requirements to this program are one year of high school algebra and one year of laboratory science. The program is being designed to articulate with several existing upper division programs, and it is hoped that additional upper division programs will be developed to articulate more directly with this program. 


\section{Curriculum}

A draft sequence of courses was developed from the list of competencies:

Semester 1

Introduction to Technology

Multimedia Presentations I (Graphics for Computer Authors and Presenters)

Product Maintenance I (digital electronics)

Research, Composition, and Presentation I (RCP)

Mathematics I

Science I

Semester 2

Humanities Elective

Multimedia Presentations II

Product Maintenance II (analog electronics)

RCP II

Mathematics II

Science II

Semester 3

Product Installation (PC's, LAN's, servers, cabling)

Teleconferencing I (desktop video conf., audio/video basics)

Social Science Elective

RCP III

Mathematics III

Science III

Semester 4

Remote \& Automated Testing

Teleconferencing II (ISDN, WAN's, wide area video conferencing)

Physical Education

Technical Elective

Mathematics IV

Science IV

This two-year sequence of courses is being developed with the following criteria in mind: A first semester course called "Introduction to Technology" is being developed to service all of the engineering technology programs. This course will be utilized for the telemedia students. A strong four semester mathematics and science sequence will be developed. The four semester sequence is to implement the "just in time" nature of the program. A three semester sequence of research, communications, and presentation (RCP) will provide material equivalent to a twosemester college English Composition sequence.

As can be seen by the courses, the first year is devoted to foundation material in addition to the courses in multimedia presentation. Courses which cover basic digital and analog circuits and electronics are included. All of these courses will contain substantial amounts of computer familiarization together with computer based instruction where appropriate.

While the main focus of the program is telecommunications, it is important to include a graphics art component, and to insure that students become familiar with the essentials of available 
presentation software. A course entitled "Graphics for Computer Authors and Presenters" will enable students to develop skills associated with color composition, slide presentations with captured video pictures and spreadsheets, and animated slides. This can be described as a static presentation course. The second course, described as dynamic presentations, will develop skills associated with interactive materials such as video clips and audio, CD-ROM mastering, and web page uploading. The interdisciplinary nature of this program requires the expertise of several college departments and represents a team effort. Our curriculum committee is composed of members of the Physics/Electrical Engineering department where the program is housed, as well as the Computer Science, Mathematics, and English departments.

The second year technical courses concentrate on the topics of local-area networks, wide-area networks, and video conferencing. With the on-going help of our industrial partners and other telecommunications hardware manufacturers, the members of the curriculum committee are engaged in the difficult task of developing the most appropriate equipment requirements for this program. This list of equipment is continually under revision as more information is developed. It is anticipated that actual purchase will begin in the fall of 1997. In any event, the equipment we are certain to acquire includes the following: routers, csu/dsu's, bridges, hubs, videoconferencing equipment, test equipment, ISDN switch, and associated software. Computer based training instruction will be integrated into these networking courses.

Since these second year courses will also be activity based, we are in the process of gathering industrial level projects for inclusion in the courses. Several members of our curriculum committee have been taking industrial short courses to aid in the development of these projects, and will continue to do so.

In order to improve the employability skills of graduates of this program, we will incorporate team building skill development within the sequence of courses. Team building competencies will be introduced in the very beginning, during the Introduction to Technology course and will be carried throughout the program.

David B. Beyer P.E. Associate Professor Physics/Electrical Engineering Technology Department Middlesex County College

Edison, NJ 08818

908-548-6000 x3004

Fax: 908-906-4662

dbeyer@email.njin.net 